\title{
In vitro comparison of passive and continuous ultrasonic irrigation in curved root canals
}

\author{
Pablo Castelo-Baz ${ }^{1}$, Purificación Varela-Patiño ${ }^{2}$, Giuseppe Cantatore ${ }^{3}$, Ana Domínguez-Perez ${ }^{4}$, Manuel Ruíz- \\ Piñón ${ }^{2}$, Ramón Miguéns-Vila ${ }^{4}$, Benjamín Martín-Biedma ${ }^{2}$
}

${ }^{1} \mathrm{DDS}, \mathrm{PhD}$, University of Santiago de Compostela, Spain

${ }^{2} \mathrm{PhD}$, University of Santiago de Compostela, Spain

${ }^{3} \mathrm{PhD}$, University Vita-Salute San Raffaele of Milan, Italy

${ }^{4}$ DDS, University of Santiago de Compostela, Spain

Correspondence:

Unit of Dental Pathology and Therapeutics II

School of Medicine and Dentistry

University of Santiago de Compostela

Rúa Entrerrios s/n 15782, Santiago de Compostela, Spain

ramon.miguens.vila@gmail.com

\author{
Castelo-Baz P, Varela-Patiño P, Cantatore G, Domínguez-Perez A, Ruíz- \\ Piñón M, Miguéns-Vila R, Martín-Biedma B. In vitro comparison of pas- \\ sive and continuous ultrasonic irrigation in curved root canals. J Clin Exp \\ Dent. 2016;8(4):e437-41. \\ http://www.medicinaoral.com/odo/volumenes/v8i4/jcedv8i4p437.pdf
}

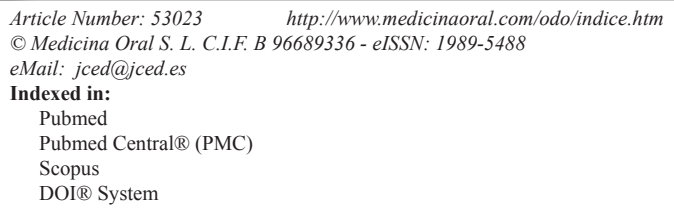

\begin{abstract}
Background: The efficacy of endodontic irrigation procedures can be compromised by the complexity of the root canal system. Delivering irrigants to the apical third of curved canals presents a particular challenge to endodontists. This study compared the effects of two ultrasonic irrigation techniques on the penetration of sodium hypochlorite into the main canal and simulated lateral canals of curved roots in extracted teeth.

Material and Methods: Two sets of simulated lateral canals were created at 2, 4, and $6 \mathrm{~mm}$ from the working length in 60 single-rooted teeth ( 6 canals/tooth, $n=360$ canals). The teeth were randomly divided into three experimental irrigation groups: group $1(n=20)$, positive pressure irrigation (PPI); group $2(n=20)$, passive ultrasonic irrigation (PUI); and group $3(\mathrm{n}=20)$, continuous ultrasonic irrigation (CUI). To assess the irrigation solution penetration, 20\% Chinese ink (Sanford Rotring GmbH, Hamburg, Germany) was added to a 5\% sodium hypochlorite solution and delivered into the curved root canals. The penetration of contrast solution into the simulated lateral canals was scored by counting the number of lateral canals $(0-2)$ penetrated to at least $50 \%$ of the total length.

Results: The CUI group showed significantly higher $(P<0.05)$ irrigant penetration into the lateral canals and into the apical third of the main canals. The PPI group showed significantly lower sodium hypochlorite penetration $(P<$ 0.001 ) into the main and lateral canals compared with that in the CUI and PUI groups. Significantly higher irrigant penetration was observed in the PUI group than the PPI group.

Conclusions: Using CUI as the final rinse significantly increased the penetration of irrigant solution into the simulated lateral canals and apical third of curved roots.
\end{abstract}

Key words: Continuous ultrasonic irrigation, curved root canals, passive ultrasonic irrigation, positive pressure irrigation, root canal irrigation. 


\section{Introduction}

One of the most important objectives of root canal therapy is to eliminate all vital and necrotic tissue, microorganisms and products of microbial degradation from the root canal system to prevent apical periodontitis (1). Root canal irrigation with an antimicrobial solution is considered an essential part of chemical/mechanical canal preparation (2). The complexity of the root canal system complicates the shaping and cleaning procedures performed by hand or using rotary instrumentation techniques (3-5). Isthmi, fins, webs, anastomoses and other irregularities within the root canal can hinder the irrigant from dissolving the organic tissues within the canal and destroying the bacterial biofilm (6).

The apical third of the root canal seems to be the most difficult part to clean because of its complex anatomy and relatively small diameter (7), which can impede the effective flow of the irrigant (8). Furthermore, root canals often have a curvature (9), which can reduce the cleaning efficacy of several irrigation techniques $(10,11)$. Positive pressure irrigation (PPI) produces irrigant exchange no farther than $1.0 \mathrm{~mm}$ beyond the needle tip (12) and is ineffective in flushing debris from the apical third of the canal without adjunctive agitation methods (13). Agitation techniques improve the apical cleaning efficacy, mechanically and chemically, by enhancing the irrigation dynamics (4).

The synergistic effects of ultrasonic energy and sodium hypochlorite in aqueous solution appear to be especially effectual (14). Currently, passive ultrasonic irrigation (PUI) is probably the most established method to activate sodium hypochlorite after root canal instrumentation $(4,15,16)$. PUI is employed to activate an irrigant using an ultrasonically activated file or tip that is not used for canal preparation. The PUI procedure encompasses the placement of the irrigant using a syringe and the subsequent activation and delivery of the irrigant through the ultrasonic hand piece. Recent in vitro studies have confirmed the efficacy of PUI in removing pulp tissue from lateral canals $(15,17)$ in straight canals and curved canals $(18,19)$. However, complete penetration of the irrigant cannot be achieved in all phases of root canal treatment (20).

Gutarts et al. (3) proposed the use of an ultrasonically activated needle placed in the canal through which the sodium hypochlorite would flow, enabling the irrigant to be replaced continually (continuous ultrasonic irrigation, CUI). In vivo and in vitro studies demonstrated the efficacy of this method in cleansing inaccessible zones of the endodontic system $(17,21)$. However, the efficacy of the CUI technique in curved canals is unknown. Likewise, it is unclear how far the CUI can reach and the effect of the root canal curvature on the depth of irrigant penetration. Therefore, the aim of this study was to compare the effects of three irrigation systems (CUI, PUI and PPI) on irrigant delivery into the apical third and simulated lateral canals of curved roots in cleared extracted teeth.

\section{Material and Methods}

-Tooth preparation

After the approval of the ethical committee (Comite de Ética de Santiago-Lugo; 2016/269), 60 extracted human single-rooted teeth with fully formed apices of maxillary lateral incisors that had not undergone prior endodontic treatment were selected. All samples had root curvatures of $20-30^{\circ}$ as determined by the method of Schneider (22), and the curvature started in the last $5 \mathrm{~mm}$ in all specimens. Teeth included in this study had a radius between 3 and $5 \mathrm{~mm}$. Each tooth was used in one experiment only. After debriding the root surface, specimens were immersed in a $5.25 \% \mathrm{NaOCl}$ solution for $1 \mathrm{~h}$ and then stored in saline until preparation. The presence of a single canal was verified radiographically and by direct exploration. The same operator performed all experimental procedures. Each specimen was sectioned to obtain a working length of $16 \mathrm{~mm}$, as described previously (17). The working length was established under a microscope (M525 F40; Leica, Heerbrugg, Switzerland) at $10 \times$ magnification with the tip of the instrument visible at the apical foramen. Each root canal was preflared using K-Flexofiles (Dentsply Maillefer, Ballaigues, Switzerland) up to \#20 and then shaped using GTX 20.04, 20.06, 30.06 (Dentsply Maillefer). Irrigation was performed with a $30-\mathrm{G}$ needle (ProRinse; Dentsply Tulsa Dental Specialties, Tulsa, OK) using 3-mL 5.25\% NaOCl after each filing. The irrigation needles were introduced passively up to $2 \mathrm{~mm}$ from the working length, and the rate of delivery was fixed at $3 \mathrm{~mL} / \mathrm{min}$. The total irrigation time was $10 \mathrm{~min} / \mathrm{specimen}$. After instrumentation, all teeth were rinsed for 3 min with 3-mL 10\% EDTA (Tubuliclean; OGNA) followed by a 3 -min final rinse with $5.25 \%$ $\mathrm{NaOCl}$. After drying with paper points, the roots were inspected under the microscope at $10 \times$ magnification to verify the canal cleanliness and absence of cracks.

After completing the shaping procedures, the teeth were cleared using the modified technique described by Robertson and Leeb (23) and prepared as described by de Gregorio et al. (5) Briefly, teeth were submerged in 5\% nitric acid for $36 \mathrm{~h}$, and the solution was renewed every $8 \mathrm{~h}$. Once decalcified, all samples were cleared with tap water for $3 \mathrm{~min}$, and lateral canals were created by inserting a $06 \mathrm{C}+$ file (Dentsply Maillefer) from the buccal to the lingual wall at 2, 4, and $6 \mathrm{~mm}$ from the working length perpendicular to the external surface. Samples were dehydrated in ascending grades of ethyl alcohol and submerged in $99.9 \%$ methyl salicylate for clearing and rehardening of dental tissues as described by Gregorio et al. (5) A total of 360 simulated lateral canals were created (6 canals/tooth, 2 lateral canals at each level).

To simulate the clinical situation, a closed system was 
created by coating each root with soft modeling wax (Cera Reus SA, Reus, Spain), and this coating sealed the apical foramen and lateral canals at all three levels (modeling wax only touch the walls, it can't penetrate into lateral canals). During this procedure, a GTX 40.06 gutta-percha point (Dentsply Maillefer) was introduced into the canal to the working length to prevent wax penetration into the canal space.

\section{-Contrast Solution}

A contrast solution containing $5 \% \mathrm{NaOCl}(80 \%)$ and $20 \%$ Chinese ink (Sanford Rotring GmbH, Hamburg, Germany) was prepared and delivered to the prepared root canals.

\section{-Experimental Groups}

The teeth were randomly divided into three experimental irrigation groups: group $1(\mathrm{n}=20)$, positive pressure irrigation (PPI); group $2(\mathrm{n}=20)$, passive ultrasonic irrigation (PUI); and group $3(\mathrm{n}=20)$, continuous ultrasonic irrigation (CUI). Irrigation was performed in the PPI (control) and PUI groups with slight modification of the methods described by de Gregorio et al. (5). Irrigation was performed in the CUI group with slight modification to the manufacturer's instructions. The irrigation time was identical for the three groups $(1 \mathrm{~min})$. All procedures were recorded under a dental operating microscope.

The teeth in group 1 ( $n=20$, control) were irrigated with PPI (1 min) using a 30-G ProRinse needle and a syringe at $2 \mathrm{~mm}$ from the working length. A total volume of 6 $\mathrm{mL}$ of contrast solution was delivered. The solution was not dynamically activated in this group.

The teeth in group $2(\mathrm{n}=20)$ were irrigated using PUI. Contrast solution (a total volume of $2 \mathrm{~mL}$ ) was delivered into the teeth using a 30-G ProRinse needle, and the solution was left in the root canals. Ultrasonic activation was performed with a blank ESI file (EMS, Nyon, Switzerland). The file was inserted passively to $1 \mathrm{~mm}$ from the working length and activated during $20 \mathrm{~s}$ using a power setting of 6 , as recommended by the manufacturer. The procedure was repeated three times, with a total volume of $6 \mathrm{~mL}$ of contrast solution and a total activation time of $1 \mathrm{~min}$ for each tooth.

The teeth in group $3(n=20)$ were irrigated using CUI. Active ultrasonic activation was performed using ProUltra PiezoFlow needles mounted on a Suprasson P5 Booster ultrasonic unit. A $10-\mathrm{mL}$ syringe containing contrast solution was attached to the luer-lock connection on the UI needle. The length at which the needle began to bind against the canal walls was determined, and the needle was then pulled back $\sim 1 \mathrm{~mm}$ and the silicon stopper was set to this depth. The insertion depth did not exceed $75 \%$ of the working length established for instrumentation; it was placed before the curvature. The inactive needle was placed into the canal, and the solution was delivered. Once irrigant filled the canal, the ultrasonic unit was activated with the power set to level 6 . Maintaining a continuous irrigation flow of $6 \mathrm{~mL} / \mathrm{min}$, the active ultrasonic tip was gently moved up and down in a consistent straight-line path from the canal entrance to the stopper setting. The total activation time was $1 \mathrm{~min}$, and a total volume of $6 \mathrm{~mL}$ of contrast solution was delivered.

-Evaluation Criteria

The samples were evaluated by direct observation of images recorded under the dental operating microscope using the criteria described by de Gregorio et al. (5) The orientation of all samples was standardized in relation to the recording microscope to produce similar images for all groups.

The penetration of contrast solution into the simulated lateral canals was scored by counting the number of lateral canals $(0-2)$ penetrated to at least $50 \%$ of the total length. The outcome was assessed in each tooth at each of the three working lengths (2, 4 and $6 \mathrm{~mm})$. Each sample scored by one trained evaluator who was blinded to the group assignment.

-Statistical Analysis

The mixed models test was used to analyze and compare irrigant penetration to the working length and into the lateral canals. $P$-values $<0.05$ were considered to indicate statistical significance.

\section{Results}

The flow of irrigant into the lateral canals and the working lengths of the root canals were analyzed in all samples $(n=20)$ in each group. A representative sample from each group is shown in figure 1 . The contrast

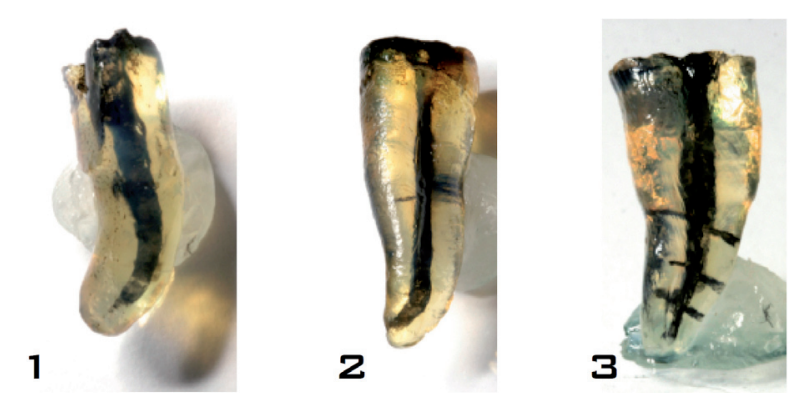

Fig. 1. 1.-PPI. 2.- PUI. 3.- CUI.

solution did not reach the working length in the group 1 samples $(0 \%)$. However, the contrast solution reached $40 \%$ of the working length in group 2 (PUI) and 90\% of the working length in group 3 (CUI). Penetration in group 1 differed significantly from that in the other two groups $(P<0.001)$. Furthermore, penetration in group 2 differed significantly from that in group $3(P<0.001)$.

Overall penetration into the lateral canals was $0 \%$ in group 1 (PPI), 46\% in group 2 (PUI), and 92\% in group 3 (CUI, Table 1). These values differed significantly among the groups $(P<0.036)$. These results were con- 
Table 1. Comparison of three irrigation systems: working length penetration and lateral canal penetration of the irrigant.

\begin{tabular}{|c|c|c|c|c|c|c|c|}
\hline & & \multicolumn{2}{|c|}{ Group 1 PPI } & \multicolumn{2}{|c|}{ Group 2 PUI } & \multicolumn{2}{|c|}{ Group 3 CUI } \\
\hline & & $n$ & $\%$ & $n$ & $\%$ & $n$ & $\%$ \\
\hline \multicolumn{2}{|c|}{ Reached working length } & $0 / 20$ & 0 & $8 / 20$ & 40 & $18 / 20$ & 90 \\
\hline \multirow{4}{*}{$\begin{array}{l}\text { Canals } \\
\text { penetrated }\end{array}$} & Overall & $0 / 120$ & 0 & $46 / 120$ & 38.3 & $92 / 120$ & 76.7 \\
\hline & $6 \mathrm{~mm}$ & $0 / 40$ & 0 & $18 / 40$ & 45 & $35 / 40$ & 87.5 \\
\hline & $4 \mathrm{~mm}$ & $0 / 40$ & 0 & $14 / 40$ & 35 & $30 / 40$ & 75 \\
\hline & $2 \mathrm{~mm}$ & $0 / 40$ & 0 & $14 / 40$ & 35 & $27 / 40$ & 67.5 \\
\hline \multirow{7}{*}{$\begin{array}{l}n \text { canals } \\
\text { penetrated }(\% \\
\text { total canals } \\
\text { penetrated) }\end{array}$} & Mean & 0 & & 0.383 & & 0.767 & \\
\hline & $\%$ & 0.0 & & $38.3 \%$ & & $76.7 \%$ & \\
\hline & SD & 0 & & 0.488 & & 0.425 & \\
\hline & Median & 0 & & 0 & & 1 & \\
\hline & IR & 0 & & 1 & & 0 & \\
\hline & Q1 & 0 & & 0 & & 1 & \\
\hline & Q3 & 0 & & 1 & & 1 & \\
\hline
\end{tabular}

Abbreviations: PPI, positive pressure irrigation; PUI, passive ultrasonic irrigation; CUI, continuous ultrasonic irrigation. IR, interquartile range; Q1, first quartile, Q3, third quartile.

firmed in separate analyses of the three levels (2, 4 and 6 $\mathrm{mm}$ ), which indicated a lower penetration rate in group 1 than in groups 2 and 3.

\section{Discussion}

Several root canal irrigation techniques and systems have been reported to improve final irrigation before obturation (24). Irrigant activation in the root canal system can enhance irrigant dispersal (25) and improve mechanical cleaning of the root canal by effective fluid flow dynamics (26). However, to our knowledge, no studies have investigated CUI into curved canals, and few studies have reported on PUI in curved canals or roots. The aim of this study was to compare the effectiveness of three irrigation techniques (PPI, PUI and CUI) in terms of delivering irrigant to the working length and into the lateral canals in curved canals.

In this in vitro investigation, we compared the efficacy of two ultrasonic techniques (PUI, CUI) with one traditional (PPI). To simulate the clinical situation, we used an in vitro closed-end canal design that closely replicates the in vivo scenario (27) in which the apical foramen is enclosed by the periodontal tissues $(3,22)$. This design forces the irrigants to exit the canal coronally rather than apically or laterally (5). As shown in our previous study (17) and in a study by de Gregorio et al. in a similar model (5), the PPI technique does not deliver irrigant to the working length and does not generate enough pressure to force the irrigants within the simulated lateral canals. Tay et al. suggested that the inability of PPI to reach the apical third may be caused by the presence of an apical vapor lock (28) created by the organic decomposition of $\mathrm{NaOCl}$ into a bubble of carbon dioxide and ammonium (5) that adversely affects the debridement effica- cy of PPI in a close-end canal design. We compared the two PUI and CUI ultrasonic techniques in curved canals. Although we employed the new nickel-titanium ESI file (EMS, Nyon, Switzerland) — which is more flexible than the stainless steel ultrasonic tips used in a previous study (17) — we found that PUI delivered adequate irrigant penetration into the apical third of only $40 \%$ of the samples. This finding suggests that PUI does not provide sufficient force to overcome the apical vapor lock after a curvature. In contrast, CUI delivered favorable penetration of sodium hypochlorite up to the working length in $90 \%$ of the samples. This group showed enough force to overcome the vapor lock, and a statistically significant difference was observed between the two groups $(P<0.001)$. This finding might be due to the continuous exchange of solution provided by the CUI technique and the optimized activation of the solution as it passes through the ultrasonically energized needle. Both ultrasonic techniques performed significantly better than PPI, as measured by irrigant penetration into the artificially created lateral canals and into the apical third. These results confirm those obtained previously, in which the efficacy of CUI was found to be significantly higher than that of PPI (18).

The CUI group received a greater volume of irrigant within the root canal system during the endodontic treatment, which is considered to be a key factor in debris removal and disinfection (29). This technique, however, has several disadvantages because its action may push the irrigants beyond the distance at which the frontal pressure of a syringe normally operates when used for canal detersion (30). Such force might compromise the safety of the cleansing procedure because of the severe consequences if sodium hypochlorite were extruded into 
the periapical tissue. Other techniques, such as the negative-pressure cleansing system, appear to be safer than manual and ultrasonic irrigation with particular reference to the ultrasonic needle; however, no clear superiority of this negative-pressure system in terms of penetration and cleansing of the endodontic space has been reported (30). To prevent the possibility of creating a ledge on the canal walls when using the CUI technique, we selected roots with curvatures in the final $5 \mathrm{~mm}$. Therefore, we reduced the risk of these ledges to allow adequate evaluation of the CUI technique into curved canals.

This investigation compared the two ultrasonic techniques (PUI and CUI) with PPI regarding the penetration depth in the simulated lateral canals. The CUI group exhibited contrast solution penetration in a significantly higher number of lateral canals, as was shown in straight canals in a previous study (17). This result might be explained by the continuous exchange of solution and the optimized activation of the solution as it passes through the ultrasonically energized needle. This finding confirms that CUI delivers irrigant more effectively than PPI or PUI into lateral canals in curved and straight roots.

\section{References}

1. Siqueira JF, Rôças IN. Clinical implications and microbiology of bacterial persistence after treatment procedures. J Endod. 2008;34:1291-301.

2. Haapasalo M, Endal U, Zandi H, Coil JM. Eradication of endodontic infection by instrumentation and irrigation solutions. Endod Top. 2005; 10:77-102.

3. Gutarts R, Nusstein J, Reader A, Beck M. In vivo debridement efficacy of ultrasonic irrigation following hand-rotary instrumentation in human mandibular molars. J Endod. 2005;31:166-70.

4. Gu LS, Kim JR, Ling J, Choi KK, Pashley DH, Tay FR. Review of contemporary irrigant agitation techniques and devices. J Endod. 2009:35:791-804.

5. de Gregorio C, Estevez R, Cisneros R, Paranjpe A, Cohenca N. Efficacy of different irrigation and activation systems on the penetration of sodium hypochlorite into simulated lateral canals and up to working length: an in vitro study. J Endod. 2010;36:1216-21.

6. Malentacca A, Uccioli U, Zangari D, Lajolo C, Fabiani C. Efficacy and safety of various active irrigation devices when used with either positive or negative pressure: an in vitro study. J Endod. 2012;38:1622-6.

7. Naïr PNR, Henry S, Cano V, Vera J. Microbial status of apical root canal system of human mandibular first molars with primary apical periodontitis after 'one visit' endodontic treatment. Oral Surg Oral Med Oral Pathol Oral Radiol Endod. 2005; 99:231-52.

8. Boutsioukis C, Gogos C, Verhaagen B, Versluis M, Kastrinakis E, Van der Sluis LW. The effect of apical preparation size on the irrigant flow in root canals evaluated using an unsteady Computational Fluid Dynamics model. Int Endod J. 2010;43:874-81.

9. Cunningham C, Senia E. A three-dimensional study of canal curvatures in the mesial roots of mandibular molars. J Endod. 1992;18:294300 .

10. Amato M, Vanoni-Heineken I, Hecker H, Weiger R. Curved versus straight root canals: the benefit of activated irrigation techniques on dentin debris removal. Oral Surg Oral Med Oral Pathol Oral Radiol Endod. 2011;111:529-34.

11. Rödig T, Döllmann S, Konietschke F, Drebenstedt S, Hülsmann M. Effectiveness of different irrigant agitation techniques on debris and smear layer removal in curved root canals: a scanning electron microscopy study. J Endod. 2010;36:1983-7.
12. Gao Y, Haapasalo M, Shen Y, Wu H, Li B, Ruse ND, et al. Development and validation of a three-dimensional computational fluid dynamics model of root canal irrigation. J Endod. 2009;35:1282-7.

13. Ahmad M, Pitt Ford TR, Crum LA, Walton AJ. Ultrasonic debridement of root canals: acoustic cavitation and its relevance. J Endod. 1988;14:486-93.

14. Blume T, Neis U. Improving chlorine disinfection of waste water by ultrasound application. Water Sci Technol. 2005;52:139-44.

15. Van Der Sluis LW, Versluis M, Wu M, Wesselink PR. Passive ultrasonic irrigation of the root canal: a review of the literature. Int Endod J. 2007;40:415-26.

16. Plotino G, Pameijer C, Grande N, Somma F. Ultrasonics in endodontics: a review of the literature. J Endod. 2007:33:81-95.

17. Castelo-Baz P, Martin-Biedma B, Cantatore G, Ruíz-Piñón M, Bahillo J, Rivas-Mundiña B, et al. In vitro comparison of passive and continuous ultrasonic irrigation in simulated lateral canals of extracted teeth. J Endod. 2012;38:688-91.

18. Al-Jadaa A, Paque F, Attin T, Zehnder M. Acoustic hypochlorite activation in simulated curved canals. J Endod. 2009;35:1408-11.

19. Malki M, Verhaagen B, Jiang LM, Nehme W, Naaman A, Versluis $\mathrm{M}$, et al. Irrigant flow beyond the insertion depth of an ultrasonically oscillating file in straight and curved root canals: visualization and cleaning efficacy. J Endod. 2012;38:657-61.

20. Vera J, Arias A, Romero M. Effect of maintaining apical patency on irrigant penetration into the apical third of root canals when using passive ultrasonic irrigation: an in vivo study. J Endod. 2011;37:1276-8.

21. Carver K, Nusstein J, Reader A, Beck M. In vivo antibacterial efficacy of ultrasound after hand and rotary instrumentation in human mandibular molars. J Endod. 2007;33:1038-43.

22. Schneider SW. A comparison of root canal preparations in straight and curved canals. Oral Surg Oral Med Oral Pathol Oral Radiol Endod. 1971;32:271-5.

23. Robertson DC, Leeb IJ. The evaluation of a transparent tooth model system for the evaluation of endodontically filled teeth. J Endod. 1982;8:317-21.

24. Boutsioukis C, Lambrianidis T, Kastrinakis E. Irrigant flow within a prepared root canal using various flow rates: a computational fluid dynamics study. Int Endod J. 2009;42:144-55.

25. Moorer WR, Wesselink PR. Factors promoting the tissue dissolving capability of sodium hypochlorite. Int Endod J. 1982;15:187-96. 26. Jiang LM, Verhaagen B, Versluis M, van der Sluis LW. Evaluation of a sonic device designed to activate irrigant in the root canal. J Endod. 2010;36:143-6.

27. Usman N, Baumgartner JC, Marshall JG. Influence of instrument size on root canal debridement. J Endod. 2004;30:110-2.

28. Tay FR, Gu LS, Schoeffel GJ, Wimmer C, Susin L, Zhang K, et al. Effect of vapor lock on root canal debridement by using a side-vented needle for positive-pressure irrigant delivery. J Endod. 2010;36:74550 .

29. Howard RK, Kirkpatrick TC, Rutledge RE, Yaccino JM. Comparison of debris removal with three different irrigation techniques. J Endod. 2011;37:1301-5.

30. Desai P, Himel V. Comparative safety of various intracanal irrigation systems. J Endod. 2009;35:545-9.

\section{Conflict of Interest}

The authors deny any confict of interest. 